Soumya Swaminathan, no life is worth more in one part of the world than in another. The world must continue to honor that.

\section{Moses Alobo ${ }^{凶}$}

Alliance for Accelerating Excellence in Science, Africa-African Academy of Sciences, Nairobi, Kenya.



Published online: 10 June 2021

https://doi.org/10.1038/s41591-021-01395-6
References

1. African Academy of Sciences, African Union Development Agency, UK Collaborative on Research Development \& The Global Health Network. The African Academy of Sciences https://www.aasciences.africa/publications/ update-research-and-development-goals-covid-19-africa (2020).

2. African Union, African Centers for Disease Control, World Health Organization \& African Academy of Sciences. World Health Organization Regional Office for Africa https://www.afro. who.int/publications/research-and-development-priorities-covid19-africa (2020).

3. Barasa, E., Ouma, P. O. \& Okiro, E. A. PLoS One 15 e0236308 (2020).

4. Kaja, A. et al. Lancet 8, e1264-e1272 (2020).
5. Sagan, A. et al.. Eurohealth https://apps.who.int/iris/bitstream/ handle/10665/336290/Eurohealth-26-2-20-24-eng.pdf (2020).

\section{Acknowledgements}

D.-F. Ndlovu, communications manager, AAS/AESA, offered support in the writing of this article. M.A. leads the Grand Challenges Africa program at the Alliance for Accelerating Excellence in Science in Africa, a platform of the African Academy of Sciences, African Union Development Agency (AUDA-NEPAD) and global partners.

The author declares no competing interests.

\title{
Emergence of measles during the COVID-19 pandemic threatens Pakistan's children and the wider region
}

To the editor - In a recent Correspondence by Durrheim et al., the authors described the looming threat of measles amid the COVID-19 pandemic ${ }^{1}$. We agree with the concerns raised by the authors, as shown by the alarming measles outbreak now ongoing in Pakistan, concurrent with the COVID-19 pandemic.

Measles is one of the most contagious viral diseases and is a leading cause of morbidity and mortality, with around 2.6 million annual deaths worldwide. The basic reproduction number of 12 to 18 for the measles virus is the highest of any respiratory virus, and is much higher than that of the coronavirus SARS-CoV-2, the cause of COVID-19 ${ }^{1}$. Despite the availability of a safe and effective vaccine against measles, many countries have experienced measles outbreaks in recent years. In 2019 , there was a precipitous increase in measles outbreaks worldwide, with 413,308 confirmed cases and 207,500 measles-related deaths, compared with 140,000 deaths in $2018,110,000$ deaths in 2017 , and 89,780 deaths in 2016 (refs. ${ }^{1,2}$ ).

Pakistan stands among the top five countries with the largest number of children not vaccinated against measles in 2021, and therefore has the highest toll of measles cases, along with Yemen, Tanzania, India and Nigeria ${ }^{3}$. Measles has been endemic in Pakistan for decades and accounts for $65 \%$ of the total measles burden among 22 countries in the Eastern Mediterranean region ${ }^{4}$.

Since its emergence in December 2019, the COVID-19 pandemic has become a

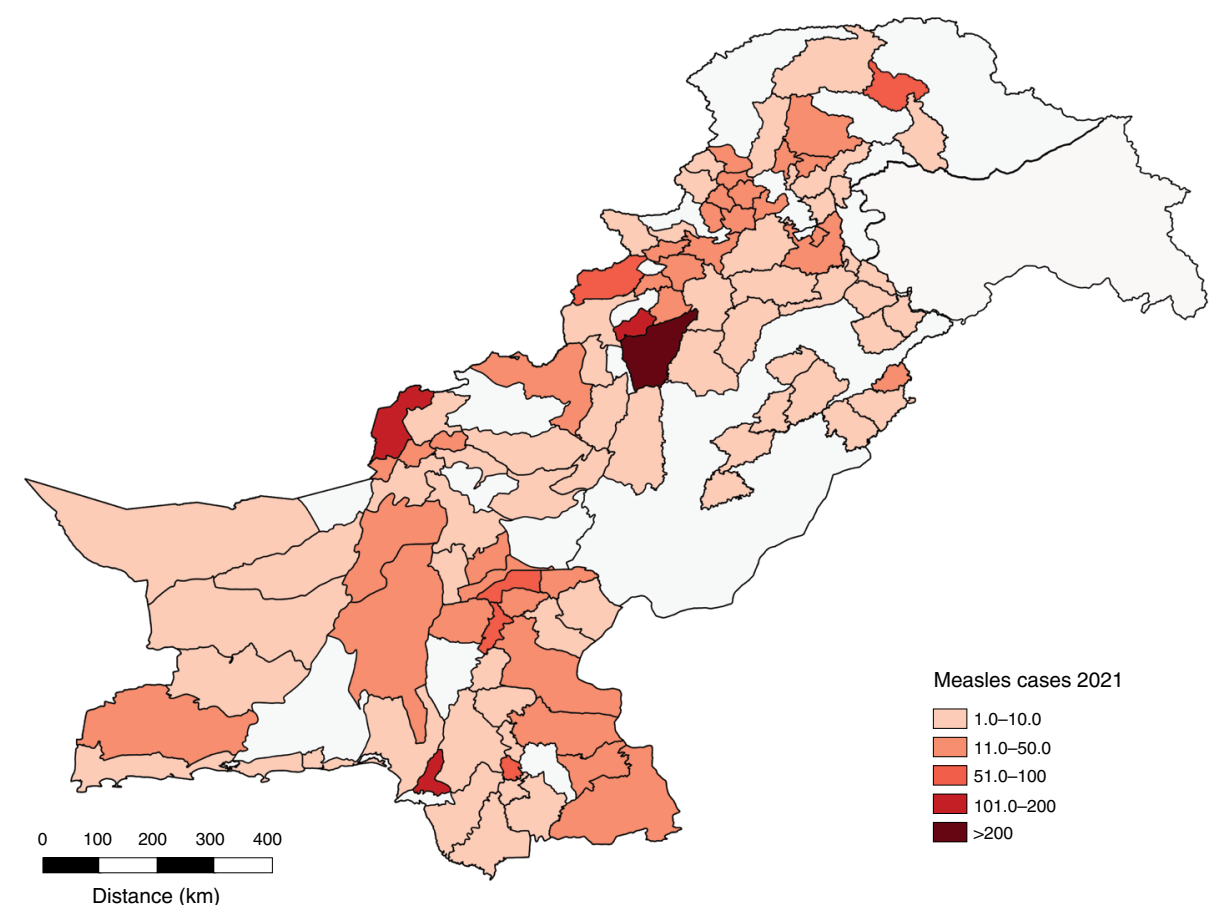

Fig. 1 | The locations of positive measles cases reported in 2021 across Pakistan. Publ. note: Springer Nature is neutral about jurisdictional claims in maps.

worldwide public-health disaster, with more than 172 million confirmed cases and 3.7 million deaths (as of 4 June 2021) reported globally ${ }^{5}$. Likewise, in Pakistan, the toll of confirmed COVID-19 cases reached more than 928,000 , including more than 21,000 deaths, since 26 February 2020 (ref. ${ }^{5}$ ). The third wave of COVID-19 is intensifying in Pakistan and coincides with an unprecedented rise in measles outbreaks across the country, with 79 notified outbreaks, 8,054 confirmed cases and 47 deaths since January 2021 (Fig. 1). 65\% of the total case count comprises children below 5 years of age, $78 \%$ of whom were found to be unvaccinated. 


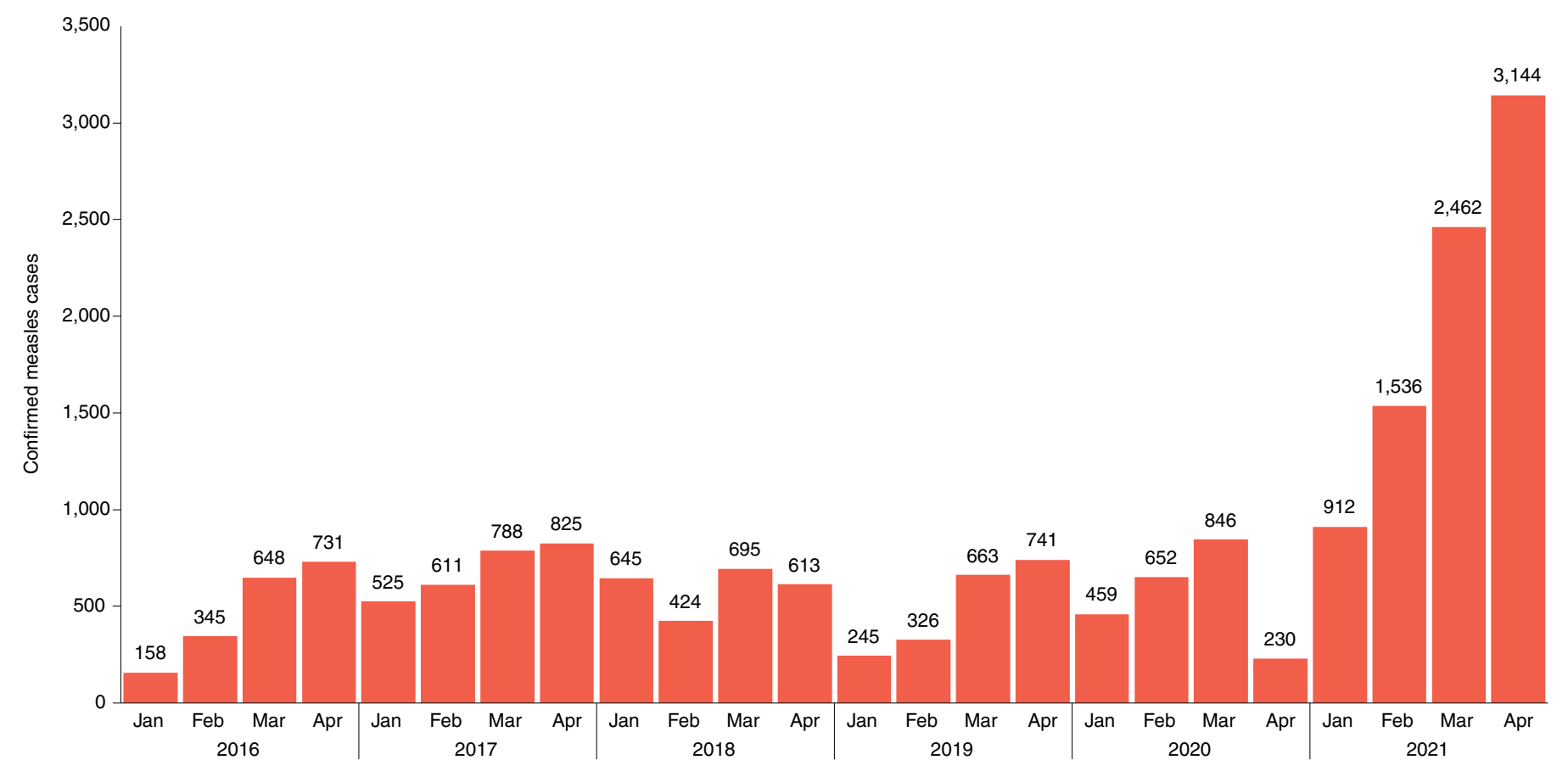

Fig. 2 | Confirmed measles cases over time. Cases reported in the first 4 months of the past 6 years (January through April, 2016-2021).

This is, sadly, no surprise, as globally, more than 120 million children were unable to receive the vaccine against measles in 2020; 40 million of these children are in Pakistan ${ }^{6}$. Suspension of childhood immunization programs might seem helpful for containment of the COVID19 pandemic, but it has triggered other public-health disasters, including measles. The risk of a measles epidemic is heightened in Pakistan, as the country has had a low level of routine immunization coverage for many years, with less than $66 \%$ coverage for the first dose of measles-containing vaccine in 2018 , and $45 \%$ for the second dose, far below the $90 \%$ coverage required for herd immunity.

In 2020, the COVID-19 pandemic resulted in a historic $65 \%$ decrease in immunization activity among Pakistan and India and an estimated $21.3 \%$ increase in child mortality that resulted in 228,000 deaths in children under 5 years of age in South Asian countries, including Pakistan ${ }^{7}$. Although children infected with SARS-CoV-2 rarely have a severe infection, co-infection with measles virus may lead to serious complications, in part due to measles-induced immunological amnesia ${ }^{8}$. Reports indicated that before the COVID19 pandemic, nearly $54 \%$ of Pakistani children were malnourished and vitamin A deficient, which led to immunodeficiency and accounted for $35 \%$ of the total childhood deaths in the country 9 . The COVID-19 pandemic has further increased the proportion of nutritionally deficient children in Pakistan due to disruptions in nutrition and essential services, which coincides with a $30 \%$ increase in measles incidence among children under 5 years of age, relative to its incidence in the pre-pandemic period (Fig. 2).

Pakistan spends less than $1 \%$ of its gross domestic product on the health sector, which is wholly inadequate in the fifth-most-populous country in the world, with regular outbreaks of vaccine-preventable diseases, including measles, rotavirus, poliomyelitis-and now COVID-19. The control and prevention of measles requires sustained and robust routine immunization programs coupled with supplementary measles-vaccination campaigns.

Multiple local challenges, such as low investment in the public-health sector, lack of medical services, malnutrition, vaccine hesitancy and complacency, high population density, public negligence, and now the COVID-19 pandemic, are likely to further increase the incidence and case-fatality rate of measles in Pakistan this year. Maintaining good immunization coverage is of the utmost importance to control and prevent further measles outbreaks. If the circulation of measles in Pakistan is not quickly stopped through vaccination, this outbreak could spell disaster for the stretched healthcare system of the country, and could also pose a grave risk to Pakistan's neighbors-for as with SARS-CoV-2, the measles virus knows no borders.

Muhammad Suleman Rana ${ }^{1 凶}$,

Muhammad Masroor Alam',

Aamer Ikram', Muhammad Salman',

Mohammad Osama Mere ${ }^{2}$,

Muhammad Usman', Massab Umair ${ }^{1}$,

Syed Sohail Zahoor Zaidi ${ }^{1}$ and Yasir Arshad

${ }^{1}$ National Institute of Health, Islamabad, Pakistan.

${ }^{2}$ World Health Organization, Islamabad, Pakistan.

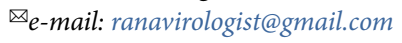

Published online: 28 June 2021

https://doi.org/10.1038/s41591-021-01430-6

References

1. Durrheim, D. N. et al. Nat. Med. 27, 360-361 (2021).

2. Rana, M. S. et al. J. Infect. 82, 414-451 (2021).

3. Centers for Disease Control and Prevention. https://www.cdc. gov/globalhealth/measles/data/global-measles-outbreaks.html (accessed 22 May 2021).

4. Dawn https://www.dawn.com/news/1520931 (7 December 2019).

5. Worldometer. https://www.worldometers.info/coronavirus/ (accessed 2 June 2021).

6. Guha-Sapir, D. et al. Science 369, 261-261 (2020).

7. $B B C$ News https://www.bbc.com/news/world-asia- 56425115 (17 March 2021).

8. Mina, M. J. et al. Science 366, 599-606 (2019).

9. Asim, M. \& Nawaz, Y. Children 5, 60 (2018).

\section{Competing interests}

The authors declare no competing interests. 